\title{
Warehouse Management System of a Third Party Logistics Provider in Malaysia
}

\author{
Vellian Vatumalae ${ }^{1}$, Premkumar Rajagopal ${ }^{2}$, Veera Pandiyan Kaliani Sundram ${ }^{3}$ \\ ${ }^{1}$ Institute of Post Graduate Studies, Malaysia University of Science and Technology, Selangor, Malaysia \\ ${ }^{2}$ Malaysia University of Science and Technology, Petaling Jaya, Malaysia \\ ${ }^{3}$ Department for Technology \& Supply Chain Management, Faculty of Business and Management, Universiti \\ Teknologi MARA, Malaysia
}

Correspondence: Vellian, Institute of Post Graduate Studies,Malaysia University of Science and Technology, Kota Damansara, 47810 Petaling Jaya, Selangor, Malaysia. E-mail: vellianv@ yahoo.com.my

Received: May 18, 2020

doi:10.5539/ijef.v12n9p73
Accepted: July 28, 2020

Online Published: August 15, 2020

URL: https://doi.org/10.5539/ijef.v12n9p73

\begin{abstract}
This study aims to explore the significant benefits gained from the implementation of the Warehouse Management System in 3rd Party Logistics Service Provider. A qualitative research approach been adopted by conducting an in-depth case study in one of Halal third-party logistics (3PLs) company located in central Malaysia, offering most of the logistics services, including transportation and warehousing. Information obtained from the warehouse operations managers in understanding the overall benefit of the warehouse management system. As a result of the highly competitive in 3rd party logistics market, environment companies are continuously forced to improve their warehousing operations into a system based applications. Many 3rd party logistics companies have also customized their value proposition to meet better customer demands, which has led to changes in the role of warehouses. The findings of this study have significant implications for both academicians and the 3PLs organizations to further explore the theories, practices, and the implementation of the Warehouse Management System in the warehouse operations. The future studies may lead to an investigation of the relationship of the warehouse management system with 3PL business competitiveness among the 3PL's organization.
\end{abstract}

Keywords: warehouse management system, warehouse operations performance, warehouse key performance indicator, 3rd party logistics, halal warehouse operations

\section{Introduction}

According to the Logistics Glossary, the definition of Third Party Logistics (3PL) services as:- outsourcing all or much of a company's logistics operations to a specialized company. According to Robinson (2014), the term "3PL" was first used in the early 1970s with main focus is to identify intermodal marketing companies (IMCs) in transportation contracts however the definition has broadened to the point where nowadays, every logistics firm that offers some kind of logistics service has been rebranded as a 3PL in such services the 3PL provided inclusive of transportation or freight management (including warehousing technology, freight management, accounting, and services around claims), public and or contract warehousing, freight consolidation and distribution management

Traditionally, a warehouse is a supply chain facility or center for consolidate products, to eliminate the transportation cost and achievement of scale in manufacturing or in purchasing (Bartholdi \& Hackman, 2006) or provide value-added processes and shorten response time (Gong \& De Koster, 2008). Recently the warehousing industry has also been identified as one of the key operations in supply chain where the warehouse providers companies can offer tailored services for their customers and achieve competitive advantage in the marketplace. There are various types of warehouses: they can be classified into production warehouses and distribution centers (Ghiani, Laporte, \& Musmanno, 2004) and by their roles in the supply chain the type of warehouses can be classified as raw materials warehouses, work-in-process warehouses, finished goods warehouses, distribution warehouses, fulfillment warehouses, local warehouses directly to customer demand, and value-added service warehouses by their position in the supply chain network (Frazelle, 2001). 
A warehouse is very important for every business particularly for the production and retail sector, but also for the entire supply chain. The term of the warehouse is often mentioned in a negative context, as the operations of the warehouse causes high costs, waste of time and without adding value to the product. Such understanding of the process of warehouse management and warehousing are limited and does take into account of the main activities of warehouse management such as: reducing the warehouse costs and inventory holding, increasing warehouse efficiency, increasing inventory accuracy, increasing productivity while achieving greater value for customers and higher levels of service quality (Richards, 2014). The warehouse operation plays key functions in the supply chain connecting the material movement between the manufacturer and the customer. As a result of the highly competitive market environment, companies are constantly pressured to enhance their warehousing operations in system-based applications (Frazelle, 2001).

Most 3PL companies have also modified their value proposition to meet better customer requirements, which has contributed to improvement in the efficiency of warehouses. In these situation, enhancement of the order processing cycle times, the inventory management and the performance of the operations. According to Murray (2012), Warehouse Management Systems (WMS) have been available since the earliest computer systems was introduced and were equipped with a simple storage location functionality. Today the WMS application can be standalone or part of an Enterprise Resource Planning (ERP) program and can incorporate with complex technology such as Radio Frequency Identification (RFID) and voice recognition. However, the basic concept of the warehouse system remained the same, which is to provide detail information for an efficient monitoring of the movement of materials within the warehouse. The Warehouse Management system (WMS) is a part of the Supply Chain Management component and Warehousing operation solutions as shown in Figure 1.

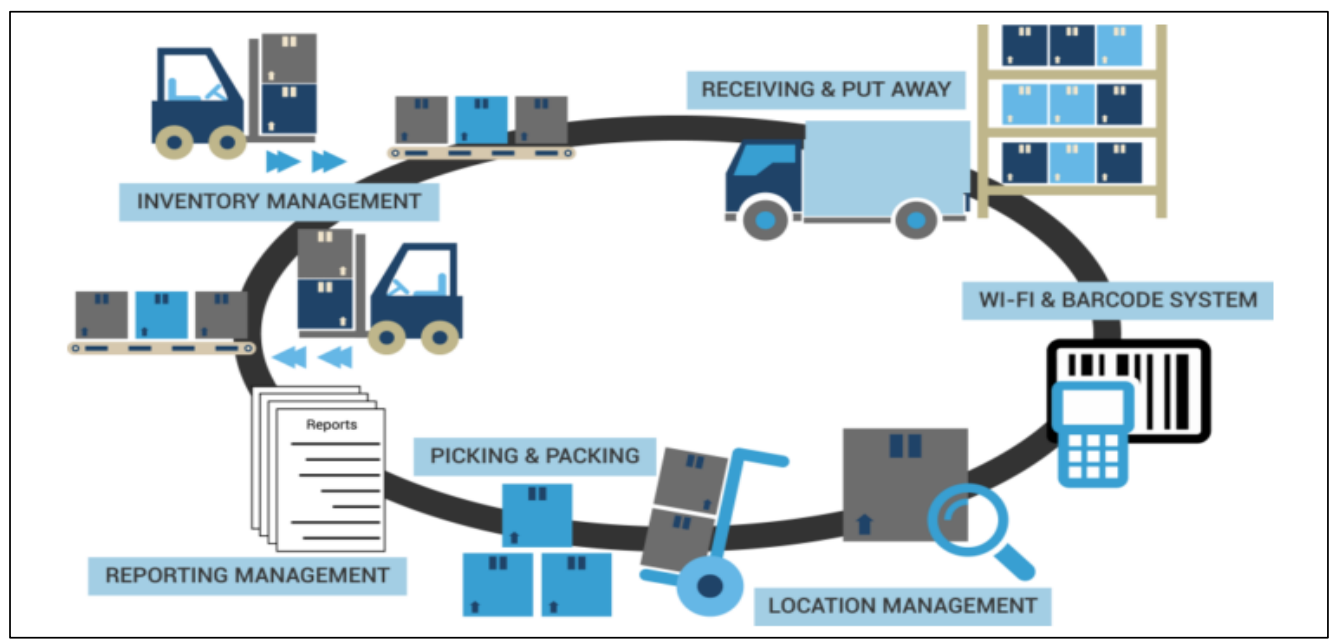

Figure 1. Warehouse management system

Source: Martin Murray, 2012.

According to Ramaa (2012), a warehouse management system or WMS main purpose is to monitor the movement and storage of materials within a warehouse and to process the relevant transactions, including receiving, put-away, picking and shipping.

A warehouse management system (WMS) is a database- driven computer program designed to increase the warehouse performance efficiency by directing putaways and maintaining high accuracy of inventory through recording warehouse transactions. The systems have also direct and managed the stock holding based on real-time information captured on the status of bin utilization. The warehouse management system used the Auto ID Data Capture (AIDC) technology such as barcode scanners, handheld computers, wireless LANs (Local Area Network) and eventually Radio-frequency identification (RFID) to efficiently manage and monitor the movement of goods within the warehouse facility.

When the transaction data has been processed, either batch synchronization with or a real-time wireless transmission to a central database is performed. The database will then provide valuable reports on the status of goods movement in the warehouse. Given the current situation there are rapid shift of preferences of customers, orders received by warehouse companies (especially third-party-logistics) increasingly exhibit special features, 
such as smaller order sizes, higher product variety, shorter response time requests, and demands for changes after the order has been initially generated and placed (Chiang, 2011).

This indicates that although the traditional performance targets for warehouse services (e.g., warehouse utilization and efficient inventory management) still remain in today's 3PL environment, the demand of kind of warehouse services are subject to the specific, special needs of different customers. This is especially important in third-party-logistics warehouses which manage a wide range of products and a large number of individual customers. In this context the operations are expected to become more customer-oriented and to respond more effectively to requests with different characteristics and needs in very efficient manner.

According to $\mathrm{Gu}$, Goetschalckx, and McGinnis (2007), the main tasks of the warehouse operation activities concerned are to prepare and control the reception of inbound goods from suppliers, the storage of the goods, receiving orders from customers, retrieving the ordered items and assembly of the orders for outbound shipment, and distribution of the completed orders to customers. In order to achieve higher warehousing performance in term of capacity and throughput and to provide services at a minimum resource cost, warehouse resources (such as space, labour, and equipment) need to be carefully chosen, managed, and organized. Therefore, a Warehouse Management System (WMS) became essential for 3PL providers since it provides, stores, and reports the necessary information to effectively manage the flow of products within a warehouse (Faber, de Koster, van de Velde, \& Currently, 2002).

In order for any Warehouse Management System level to be able to address today's challenges and sustain its competitiveness among other WMS competition, it should possess two main characteristics:

i. Flexibility in terms of responding to short-term changes in customer demands in a reasonable time and

ii. Adaptation in terms of being able to sustain the quality of service level as customers request mid-term changes/requirements.

Although there are numerous examples in the literature of deployments using multi-agent techniques in warehouse management systems (Kim, Graves, Heragu, \& Onge, 2002; Rubrico, Ota, Higashi, \& Tamura, 2006; Rubrico, Hi Rubrico, Higashi, Tamura, \& Ota, 2011) the application of the product intelligence paradigm in warehouse management systems (WMS) and the benefits in the operations they manage is yet to be studied.

This study aims to identify the benefits in the warehouse operations not been explored in previous literature related with 3rd party logistics provider in supply chain management scope. In other words, this study may contribute new knowledge to the companies and industries, especially decision makers, managers, and policymakers, in providing effective actions to overcome warehouse operations issues and can learn what benefits and applications of warehouse management system are strongly linked to identification and what associated benefits of warehouse management system in 3rd party logistics firm that are seldom examined in the warehousing literature.

The above justifies the contribution of this paper to fill the research gap to comprehensively review the academic literature on implementation of warehouse management system in 3rd party logistics in considering its benefits and improvement that covers relevant scope of warehouse operations, technology advancement, people management, inventory accuracy and business growth of 3rd party logistics.

For the purpose of this study, Theory of Constraints (TOC) is been employed. TOC is a management philosophy created by Dr Elyahu Goldratt at the beginning of 1980 and have since developed from production technology to the philosophy it is today. According to (Goldratt, 1990), the Theory of Constraints can be applied in production, logistics, supply chain, distribution, project management, accounting, research and development, sales and marketing, and so on. This research is focused on the warehouse operations, hence this theory is strongly believed to support the entire research process in understanding the benefit of warehouse management system in 3PL.

In total this paper consists of seven parts, the first part of this paper explains in detail of the background of 3rd party logistics, warehousing management and the potential benefits of the implementation of the warehouse management system. The second part reviews extensively literature relevant to the related the warehouse management system theories adopted for this study. The third section discusses the research methodology that is deployed to meet the objectives of this research. The next part of the research paper is the discussion on the results and findings of the research. This paper also discusses the research implication for the other 3PL company's management. Research limitation and future research are elaborated in the last section before it is concluded with a summary of the study. 


\section{Literature Review}

\subsection{Warehouse Operations Efficiency}

Dave Piasecki (2001), stated although WMS continues to gain added functionality, the initial main functionality of a WMS has not improved. The primary purpose of a WMS is to control the movement and storage of materials in the operation and to process related transactions. Directed picking process, directed replenishment, and directed put away of stocks are the key functionality of the WMS. 3PLs operations required such WMS functionality due to to the complexity of their operations in the management of multi customer demand.

Faber (2002), mentioned in the word Warehouse Management System, is characterized as one or more pieces of equipment used to perform the various purposes of warehouse functions, for example the "storage system," may be nothing more than rows of pallet racks or it may include pallet racks, static shelving and floor space for holding multiple pallets of a single title. Almost all aspects of the organization have needs that affect the operations of the warehouse, particularly if they are located in the same building.

Krajewski and Ritzman (2005), explain that warehousing consist of a set of activities or processes that are carried out to ensure the smooth flow of materials and information. Assessing and improving the warehouse performance of such activities requires proper study of how warehouse flows relate to each other. Important factors that influence process efficiency in the warehousing storage environment are for example,layout choices and policies that control the work routines. It has also been argued that the flow of information between different stage of a process could be improved significantly besides trying to take advantage of information technology and increasing the level of automation.

Nasir Ayub (2007) indicated the warehouse management systems (WMS) is best defined as advanced technology and operating processes that automate all warehousing operational functions, usually these functions typically begin with receipts from suppliers and end with shipments to customers and involve all inventory movements and information flows in between them. Warehouse management systems have traditionally been associated with broader , more complex distribution operation management.

According to Baker (2004), it is difficult to deploy a warehouse management system and challenging because it requires too many trade-off decisions. Every warehousing function needs to be carefully implemented in order to achieve operational objectives. These targets are also expressed in terms of capacity, throughput, and the level of customer service.The literature also recognizes that the design process for the warehouse system is highly complex particularly in the 3PL operations in the management of multi customer's requirements. The authors also seem to resolve this complexity by explaining the sequenced procedures for developing an appropriate warehousing solution.

\subsection{Inventory Accuracy}

Faber (2002), stated in the old days of warehousing, has been shown the inventory to reflect to represent the wealth of a business. Nevertheless, that is no longer the case these days. Instead, many companies have noticed the high cost associated with holding inventory. In their purest form, warehouses will be transshipment areas for distribution and receiving where products remain in the warehouse for a short period of time only. In addition, however there are main factors as overriding factors such as meeting customer demand and expectations that make it difficult to operate without inventory.

Gunasekaran (2004), which states that warehousing also plays an important role from the point of supply chain perspective. Despite all of the integration initiatives, supply chains will never be so well organised that warehousing can be completely eliminated (Sundram et al., 2016). Baker (2004) describes a warehouse management system, or WMS, is a crucial part of the supply chain and mainly concerned with managing control the material movement and storage within a warehouse and handling the related transactions, including receiving, put away, picking and shipping.

Croxton (2003), mentioned a warehouse management system is now considered as a framework in order to strengthen and improve the logistics of businesses and organizations. It can help to enhance control over the different warehouse operations, from receiving and storing different goods or products up to the extracting and delivering the said products.

Phillips (2010), indicated today that warehouse management is part of Supply Chain Management and Demand management. Even the management of production is largely dependent on the management of warehouses. Efficient warehouse management gives retail chain distribution company the cutting edge. Warehouse management not only starts with receipt of material, but it also starts with actual initial preparation when container design is made for the product. Warehouse design and process design within the warehouse (e.g. Wave 
Picking) are also part of warehouse management. Warehouse management are also part of Logistics and Supply Chain Management. Warehouse Management tracks the progress of products movement through the warehouse.

\section{Methodology of Research}

Case studies are usually in a form where such research is time constrained, and thus researchers use multiple means to gather data within the limited time frame (Dodge, 2011). This study is in the form of an exploratory research which uses qualitative means to gather data in regard to the benefit of the Warehouse Management System in 3PL. Such naturalistic qualitative case study mainly focus on the subject matter in a context-specific and true setting, where information collection is not be manipulated (Patton, 2002). Qualitative research is chosen as the means for this case study. This segment describes detailed case study methods, inspects the application of case study methods, and also investigates the particular detail and accuracy of case study methods. Every segment of the exploration outline needs aid associated.

Table 1. 3PL company background

\begin{tabular}{ll}
\hline Company & Description \\
\hline ABC Logistics (M) Sdn & Established in Malaysia by 2001, 3rd Party Logistics Provider, based in Puchong Industrial Park. The 3rd \\
Bhd & Party Logistics Provider are servicing 55 multi composite customers with 3PL contract Warehouse service. \\
& This 3rd Party Logistics Provider are providing Frozen and Chill Temperature Warehousing facilities and \\
& Transportation (trucking) services mainly for Frozen and Chill Temperature control products. Basically this \\
& 3rd Party Logistics Provider are well known in the Malaysia Logistics Industry as one of the main player for \\
& temperature controlled logistics. The trademark of this company is Halal Logistics, where this company is \\
& the first JAKIM (Jabatan Kemajuan Islam Malaysia) certified Halal. \\
\hline
\end{tabular}

\subsection{Study Setting}

Qualitative case study applies a naturalistic technique that is on the lookout for getting learning that has happened in a specific setting, such as, the actual experience where the researcher does not strive to control or influence the occurrence of interest (Patton, 2002). However, in order for the study to be credible, the researcher have to test the credibility, validity and reliability of the research study. Basically, a qualitative case study, the researcher is the instrument of the research (Patton, 2002). As a consequence, it appears to be a qualitative research's credibility which relies on capability, exertion and application of the researcher (Dodge, 2011). Despite validity and reliability would approach independently for quantitative research, these terms are not seen independently on qualitative research (Bashir, Afzal, \& Azeem, 2008). Instead, of wording that includes both, like credibility, dependability and reliability may be utilised (Golofshani, 2003).

\subsection{Sampling and Data Collection}

The purposive sampling method is used as the data required to be collected can only be obtained from specific target groups who have the specific data needed. There are two types of sampling methods involved in purposive sampling (Sekaran \& Bougie, 2010). For this research, judgment sampling is used, where the data are collected only from the selected few persons who is expertized on the field obtain the first-hand information required. The sampling unit is known as a person or a group of people that is used to collect the data for the sampling process (Sekaran \& Bougie, 2010). The research data will be collected from the warehouse manager, assistant warehouse managers and stock control manager in the company.

These persons are in charge and knowledgeable in regard to the warehouse operations activity in the company Non-probability sampling design is used in this research, data collected will be used to analyses the understand the benefits of the Warehouse Management System in 3PL warehouse operations.

Table 2. Respondent detail in the 3PL

\begin{tabular}{|c|c|c|c|c|c|}
\hline Company & Respondent Designation & Gender & $\begin{array}{c}\text { Work Experience } \\
\text { (Years) }\end{array}$ & $\begin{array}{c}\text { Highest Educational } \\
\text { Qualification }\end{array}$ & $\begin{array}{c}\text { Interview Durations } \\
\text { (Minutes) }\end{array}$ \\
\hline ABC Logistics (M) & Warehouse Manager & Male & $>20$ years & Bachelor's Degree & 60 minutes \\
\hline \multirow[t]{4}{*}{ Sdn Bhd } & Stock Control Manager & Male & $>15$ years & SPM & 65 minutes \\
\hline & Assistant Warehouse Manager & Male & $>15$ years & Diploma & 55 minutes \\
\hline & Assistant Warehouse Manager & Male & $>13$ years & Diploma & 75 minutes \\
\hline & Assistant Warehouse Manager & Male & $>10$ years & Diploma & 70 minutes \\
\hline
\end{tabular}


Tashakkori and Creswell (2007), indicated that qualitative research generating hypotheses involves collecting interview data from research participants concerning a phenomenon of interest, and then using what they say to develop hypotheses. A powerful mixed methods analysis, either quantitative or qualitative, should start with a mixed methods research query,shape the methodology, provide the best detail information on the research questions, hypotheses and the overall design of a study. The quality of data refers to the usable information obtained from the interviewee, for this case study, as scope is quite narrow, there are limited number of candidates that fits to provide the information required for this study. Hence, the warehouse manager, assistant warehouse manager, and stock control manager in the department were chosen as the sample to obtain information based on their experience and knowledge on the benefit of the Warehouse Management System in their warehouse operations.

\subsection{Research Instrument}

Research instrument is a supportive tool for this research study, and it occurs under two different categories. The two different types of research instruments are researcher completed instruments (researchers administer) and subject-completed instruments (completed by respondents) (Bashir, Afzal, \& Azeem, 2008). A checklist of key points of the variable outcomes and a set of semi structured questions that derived from the research questions was chosen as the research instrument. Data from the respondents were captured while the interviews took place at their premise. For this purpose of the research, the researcher has adopted Creswell (2014) proposed more precise steps that need to be followed to perform data analysis in qualitative research. These steps include; organizing and transcribing the data for analysis, exploring the data and developing codes and describing and developing themes (categories).

\section{Findings and Discussion}

Analysis indicates that all five respondents have similar perception towards the benefits of the warehouse management system in the 3PL warehouse operations. The warehouse management system has improved the operations process related with the all the warehouse activities. The warehouse activities in the 3PL are inclusive of unloading, receiving, put away, picking and dispatch activities.

Each process in the warehouse operations has been simplified with the warehouse management system hence the benefits obtained in improving the warehouse operations towards the customer orders. The respondents are comfortable with the implementation of warehouse management system by the 3PL as this strategy will enhance the competitive advantages among other 3PL that offer the same warehouse services in Cold Chain Industry. Table 3 shows the Theme derived from this research. The Theme mainly focused on the warehouse operations efficiency and inventory record accuracy benefited from the implementation of the warehouse operations management in the 3PL.

Table 3. Theme of warehouse management system benefits from 3PL

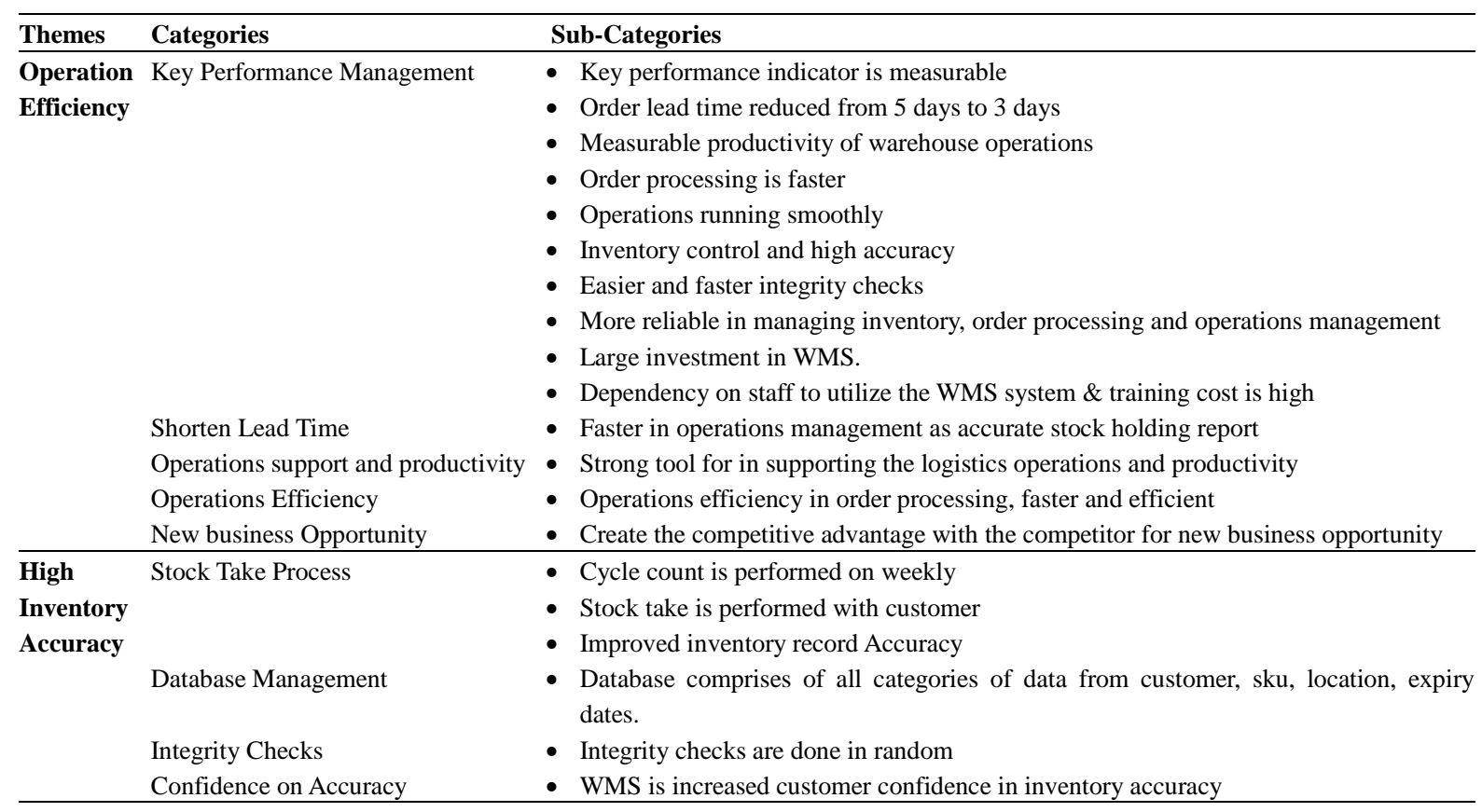




\subsection{Benefits in Warehouse Operations Efficiency}

All respondents agreed that the benefits are on the resource key performance index related with the operations efficiency are more measurable. The system able to track the performance of the team on the assigned job in term of their performance in productivity of the operations handling cases on receiving, picking and despatch. The order lead time has significantly improved from 5 days to 3 days. The integrity checks related with the inventory count are easier and faster as compare to Non-WMS environment. manual goods received shall be updated into a spreadsheet as Goods Received Note and shall be communicated with the customer. The order processing window from the day customer placed the order till the orders dispatched to the customer improved significantly with the implementation of the Warehouse Management System. The time savings are derived from the implementation of the system where the data entry is performed thru the radio frequency and automatically the goods received information been transferred into the auto printed Goods Received Note. The customers are able to see the auto goods Received Note thru the B2B System.

\subsection{Benefits in Customer Order Lead Time}

The improvement of order lead time has significantly improved the efficiency of the warehouse operations. The warehouse operations team are able to process the order in a fast mode with waving the orders through the system. The system able to perform a multi-level waving with a different customers orders. The orders waving takes approximately 5 minutes for each order that been placed. The system can match the order request from the customer based on the criteria that the customer request the goods in example of the goods with nearer expiry dates and batch numbers. The system is set with some parameter rules that enables the picking system to be flexible to meet the demand from the customers. The system later prompts the location of the goods that supposedly to be picked by the operators. Later upon the picking activity completion, the system able to prompt the dispatch notification to customer. The ABC Logistics (M) Sdn Bhd customers felt happy with the improved service level that been provided by the company.

\subsection{Benefits in Inventory Data Entry Reliability}

This refers to the reliability of the Warehouse Management System as compared to Non-Warehouse Management System in logistics operations and inventory accuracy. Based on the 5 respondents, it is concluded that Warehouse Management System are more reliable as to compare to the manual operations (Non-Warehouse Management System). The reliability comes from the significant of the technology applied in the warehouse operations where the operators are performing the data entry through the system and with this technology the warehouse management system able to minimize mistakes in the data entry by eliminating the human error found during the manual operations (Non-Warehouse Management). Further the system are capturing the real time data that been entered by the operators in which the system able to prompt the error in data entry by the operators.

In addition, all the 5 respondents has experienced the situation of accurate information through the data entry in all stages of the warehouse operations. There are four stages involved in the warehouse operations which starts from goods inbound (receiving process), put away process, picking (case and or bulk pallet) and final to dispatch the goods to the customers. The reliability in operations are seen from the integrity checks that are performed at random basis on each warehouse activities.

\subsection{Benefits in Inventory Record Accuracy}

All 5 respondents agreed that the inventory record accuracy has improved tremendously as to compared with Non-Warehouse Management System. Based on the information shared by the all respondents the current inventory accuracy is ranged up to $99 \%$. This is a good improvement ever since the company implement the step change in warehouse operations. Most contracted customers are satisfied with the improvement that derived from the Warehouse Management System. The Managing Director also has mentioned during the interview session, he has shared his experience in managing the logistics operations and inventory management with using the Non-Warehouse Management System. Based on his view the company went thru a tough time in managing the operations efficiency in term of processing the customer orders based on their demands, operations cost is very high due to lack of system to support the operations efficiency and poor inventory management as the Non-Warehouse Management System doesn't support the inventory functions. The improvement in inventory record accuracy has tremendously improved the customer satisfaction and delight on the company image as the one of the reputable 3rd partly logistics in Cold Chain business in Malaysia.

\subsection{Benefits in Customer Inventory Database}


Most respondent's views that the system inventory database that comprises the detail of the goods handled in various stage of the operations help in the inventory accuracy process. The inventory accuracy is highly depending on the database that consist of the customers information related with stock keeping unit, item master details, pack size of the products, number of cartons on a pallet based on the standard tier and high of the goods. All relevant information shall be input in the warehouse management system database. The goods flow from warehouse inbound till the outbound process shall be based on the inventory database.

The high accuracy of the keeping and maintaining the database are important in ensuring the inventory kept in the warehouse in high accuracy level. The warehouse inventory team's main task is to ensure the inventory accuracy at high level and there are specific activities involved in performing the cycle count on each week and joint count with the customers at least once in every six (6) months. The purpose of the inventory activities aimed to ensure high level of the inventory holding at all time. The high accuracy of inventory holding is significantly impact on the customer happiness and confident on the warehousing services provided by the 3rd party logistics provider. Most respondents indicated that the cycle count is performed by internal inventory team on every week. The cycle count is performed to ensure that the system inventory information on the customers goods stored in warehouse are accurate with the physical stocks kept in the chamber. Integrity checks are performed at all stage at random as part of their routine to ensure the stocks movement in and out of the warehouse are correct. Stock take is performed with the customers at least once in every 6 months.

\section{Research Implication}

The warehouse management system implemented by the company has significantly improved the inventory management. The improvement has potentially created the competitive advantage in the logistics industry. The customers are looking for more reliable service provider that giving the right service level in the warehousing in term of managing their stocks/ inventory in high accuracy level. Most of the respondents are in opinion that the implementation of the warehouse management system has improved the inventory accuracy and the improvement has potentially contributed towards a significant on customer satisfaction and delight towards the service provided. The improvement from the deploying warehouse management system has significantly improved the service and reputation of the 3rd party service provider and staying competitive in the Cold Chain Industry that potentially grows in accordance to the Government plan under the Eleventh Malaysia Plan, among the focus areas is the "Unleashing growth of logistics and enhancing trade facilitation" where Malaysia aspires to become the preferred logistics gateway to Asia, and improve its ranking in the World Bank Logistics Performance Index from top 25 in 2014 to be among the top ten by 2020. Thus, this paper serves as an evidence for top management in the 3PL to emphasize the importance of the warehouse operations efficiency and inventory record accuracy with investing in warehouse management system. The warehouse management system implementation not only for the 3PLs company but also in other industry related with warehousing that operated by in-house management such as hypermarket retailers in Malaysia. The technology advancement has brought in more choices for the management to deploy the best technology in improving the business performance especially for 3PLs. The competitive advantage with high technology advancement shall bring in more business opportunity in Malaysia 3PL markets with high in competition especially in the Cold Chain Industry. The management should focus on the customer's requirements in specializing the required warehouse services. Hence, the implementation of technological advancement in 3PL warehousing is an area that is worth exploring and stay competitive.

\section{Limitation and Future Research}

There are a few limitations to this case study. The first is the manner of the selection of candidates for the interview. Most candidate involved in this interview are the operations and stock control managers. Therefore, the inputs from a level lower than managers which includes the executive level and operators were not taken into the consideration for this interview. The interview of the executive level and below were not performed in this study due to the time constraints of this case study. The researcher believed that the executive level and below may have a in depth understanding, experience and tactical view on the operational matter that would be significant for this case study. Another limitation is that the warehouse management system functionality is rapidly growing with new features are been developed to cater the new demand in the market. The company may explore the latest development in the warehouse management system in other countries. RFID, Cross Dock and ASRS storage has been introduced in Coca Cola America to meet the new demand of the beverage industry. The exploration is part of the innovation that would give an opportunity for the 3rd party logistics to stay competitive in the Cold Chain logistics industry. For future research it is suggested to guage responses from executive and operator levels. The idea is to obtain comprehensive views on the perception and tactical information from implementation of warehouse management system. Next, it would be good to conduct an on companies that have 
implemented new version of warehouse management system, especially those that were developed to cater the new demand from customers in 3rd party logistics providers. In addition to case study approach, quantitative research is also proposed, as this will examine multiple companies involved in 3rd party logistics. This approach will provide a generalization of the WMS environment and enable to explore the extend of WMS usage in Cold Chain Industry of Malaysia.

\section{Conclusion}

In conclusion, the implementation of the Warehouse Management System in the warehouse operations significantly improved the operations efficiency and inventory accuracy. The improvement in the operations efficiency on resource planning, productivity and key performance index. The operations efficiency is a must for any 3rd partly logistics providers. Most business that involved in providing the warehouse service will focus much on the operations cost. The operations cost involved as direct and indirect will impact the level of the profitability of the company. The revenue from the business of operating the 3rd party logistics must have linked with the operations efficiency in maximizing the profit. The operations efficiency in term of the resource planning, productivity and key performance index will be measured to by the management in ensuring the right cost are spent at all time and customer satisfaction towards the rendered services should be emphasized highly in the 3rd party logistics providers in Malaysia.

\section{References}

Ayub, N. (2007). What is warehouse management system, benefit analysis 2007. Retrieved from https://www.it.toolbox.com

Baker, P. (2004). Aligning distribution center operations to supply chain strategy. The International Journal of Logistics Management, 15(1), 111-123. https://doi.org/10.1108/09574090410700266

Bartholdi III, J. J., \& Hackman, S. T. (2008). Warehouse and distribution science. Supply Chain and Logistics Institute, School of Industrial and Systems Engineering, Georgia Institute of Technology.

Bashir, M., Afzal, M. T., \& Azeem, M. (2008). Reliability and validity of qualitative and operational research paradigm. Pakistan Journal of Statistics and Operation Research, 4(1), 35-45. https://doi.org/10.18187/pjsor.v4i1.59

Chiang, D. M. H., Lin, C. P., \& Chen, M. C. (2011). The adaptive approach for storage assignment by mining data of warehouse management system for distribution centres. Enterprise Information Systems, 5(2), 219-234. https://doi.org/10.1080/17517575.2010.537784

Creswell, J. W. (2014). Qualitative Inquiry \& Research Design: Choosing among Five Approaches (4th ed.), Thousand Oaks, CA: SAGE.

Croxton, K. L. (2003). The order fulfillment process. The International Journal of Logistics Management, 14(1), 19-32. https://doi.org/10.1108/09574090310806512

Dodge, P. (2011). Managing school behavior: A qualitative case study (p. 176). Retrieved from http://www.hardis-group.com/en/our-activities/logistics solutions

Faber, N., de Koster, R. M. B., \& van de VELDE, S. L. (2002). Linking warehouse complexity to warehouse planning and control structure: An exploratory study of the use of warehouse management information systems. International Journal of Physical Distribution \& Logistics Management, 32(5), 381-395. https://doi.org/10.1108/09600030210434161

Frazelle, E. (2002). World-class warehousing and material handling (Vol. 1). New York: McGraw-Hill, 2002.

Ghiani, G., Laporte, G., \& Musmanno, R. (2004). Introduction to Logistics Systems Planning and Control. John Wiley \& Sons, England. https://doi.org/10.1002/0470014040

Golafshani, N. (2003). Understanding reliability and validity in qualitative research. The Qualitative Report, 8(4), 597-606.

Goldratt, E. M. (1990). Theory of constraints. Croton-on-Hudson: North River.

Gong, Y., \& De Koster, R. (2008). A polling-based dynamic order picking system for online retailers. IIE Transactions, 40(11), 1070-1082. https://doi.org/10.1080/07408170802167670

Gu, J., Goetschalckx, M., \& McGinnis, L. F. (2007). Research on warehouse operation: A comprehensive review. European Journal of Operational Research, 177(1), 1-21. https://doi.org/10.1016/j.ejor.2006.02.025

Gunasekaran, A., Patel, C., \& McGaughey, R. E. (2004). A framework for supply chain performance measurement. 
Production Economics, 87(3), 333-347. https://doi.org/10.1016/j.ijpe.2003.08.003

Kim, B. I., Graves, R. J., Heragu, S. S., \& Onge, A. S. (2002). Intelligent agent modeling of an industrial warehousing problem. IIE Transactions, 34(7), 601-612. https://doi.org/10.1080/07408170208928897

Krajewski, L. J., \& Ritzman, L. P. (2005). Operations management: processes and value chains (7th ed.). Upper Saddle River (NJ): Pearson Prentice Hall.

Mkumbo, F. A. E., Ibrahim, A. R., Salleh, A. L., Sundram, V. P. K., \& Atikah, S. B. (2019). The Influence of Supply Chain Practices and Performance Measurement Practices towards Firm Performance. International Journal of Supply Chain Management, 8(3), 809-819.

Murray, M. (2012). Implementing a Warehouse Management System (WMS). The Balance.

Patton, M. Q. (2002). Qualitative Research \& Evaluation Methods (3rd ed.). Sage Publications.

Phillips. (2010). Warehouse Layout Design. Retrieved from http://www.strategosinc.com/warehouse.htm

Piasecki, D. (2001). Guide to inventory accuracy, Inventory Operations Consulting LLC in Warehouse Management. Retrieved from https://www.inventoryyops.com

Rajagopal, P., Nur Atiqah, Z. A., Atikah, S. B., Appasamy, G., \& Sundram V. P. K. (n. d.). Determinants of Supply Chain responsiveness among Firms in the Manufacturing Industry in Malaysia. International Journal of Supply Chain Management, 5(3), 18-24.

Ramaa, A., Subramanya, K. N., \& Rangaswamy, T. M. (2012). Impact of warehouse management system in a supply chain. International Journal of Computer Applications, 54(1). https://doi.org/10.5120/8530-2062

Richards, G. (2014).Warehouse Management. London: KoganPage.

Robinson, A. (2014). Third Party Logistics Services Explained, the Different Types of 3PLs, and The Various Levels of Outsourcing.

Rubrico, J. I. U., Ota, J., Higashi, T., \& Tamura, H. (2006). Scheduling multiple agents for picking products in a warehouse. In Proceedings 2006 IEEE International Conference on Robotics and Automation, ICRA 2006, pp. 1438-1443. https://doi.org/10.1109/ROBOT.2006.1641911

Sekaran, U., \& Bougie, R. (2016). Research methods for business: A skill building approach. John Wiley \& Sons.

Selvaraju, M., Beleya, P., \& Sundram, V. P. K. (2017).Supply Chain Cost Reduction using Mitigation \& Resilient Strategies in the Hypermarket Retail Business. International Journal of Supply Chain Management, 6(2), 116-121.

Sundram, V. P. K., Atikah, S. B., \& Chandran, V. G. R. (2016). Supply Chain Management: Principles, Measurement and Practice. University of Malaya Press, Kuala Lumpur, 2016.

Tashakkori, A., \& Creswell, J. W. (2007). Exploring the nature of research questions in mixed methods research. Editorial Journal of Mixed Methods Research, 1(3), 207-211. https://doi.org/10.1177/1558689807302814

\section{Copyrights}

Copyright for this article is retained by the author(s), with first publication rights granted to the journal.

This is an open-access article distributed under the terms and conditions of the Creative Commons Attribution license (http://creativecommons.org/licenses/by/4.0/). 